\title{
Cultura (derecho de acceso a la) Culture (the Right to access to)
}

\author{
Mar Antonino de la Cámara \\ Universidad Autónoma de Madrid \\ mar.antonino@uam.es
}

Recibido / received: 21/01/2018

Aceptado / accepted: 07/03/2019

DOI: $\underline{\text { https://doi.org/10.20318/eunomia.2019.4705 }}$

\section{Resumen}

El doble objetivo de esta voz es: a) concretar el contenido jurídico del derecho de acceso a la cultura, para lo que se procederá a b) analizar la jurisprudencia más paradigmática del Tribunal Europeo de Derechos Humanos en relación con la protección de expresiones culturales. No se trata, pues, de una aproximación teórica a lo que sea cultura, sino de precisar, en la medida de lo posible, el alcance de un derecho poco estudiado dentro del marco geográfico europeo.

\section{Palabras clave}

Derecho de Acceso a la Cultura, Derecho a la Cultura, Derecho a la Libertad de Expresión, Libertad de creación artística, Tribunal Europeo de Derechos Humanos, Copyright

\section{Abstract}

This voice has been written with a double objective, namely a) to concretize the legal content of the right of access to culture, so we will proceed b) to analyze some of the most paradigmatic case-law of the European Court of Human Rights in relation to the protection of the culture. Therefore, it is not a theoretical approach to what is culture, but to specify the scope of a right so unstudied within the European geographical framework.

\section{Keywords}

Right of Access to Culture, Right to Culture, Right to Freedom of Expression, Right to artistic freedom, European Court of Human Rights, Copyright.

SUMARIO. 1. Introducción: ¿por qué un derecho de acceso a la cultura?. 2. El contenido sí importa. 2.1. Acceso al arte. 2.2. Cultura democrática y pluralismo. 3. Dimensión relativa y dinámica de la cultura. 4. Cultura frente a terceros. Los derechos de autor. 5. ¿Qué es el derecho de acceso a la cultura? Reflexión penúltima. 
1. Introducción: ¿por qué un derecho de acceso a la cultura?

"Las prácticas judiciales [...] son algunas de las formas empleadas por nuestra sociedad para definir tipos de subjetividad, formas de saber, $y$ en consecuencia, relaciones entre el hombre y la verdad que merecen ser estudiadas"

Michel Foucault, La verdad y las formas jurídicas

La aprobación en Estrasburgo de la propuesta de Directiva sobre derechos de autor en el mercado único digital, popularmente conocida como Directiva copyright ${ }^{1}$, y el encarnizado debate que ha suscitado en los últimos meses entre los eurodiputados ponen sobre el tapete la polémica cuestión del derecho a la cultura. Si trasladamos al punto de vista constitucional el genérico derecho humano a la cultura, podríamos concretarlo en los siguientes artículos ${ }^{2}$ : el artículo 20 de la Constitución Española (CE), que reconoce el derecho a la producción y creación literaria, artística, científica y técnica, el artículo 33 de la CE, en que se ampara el derecho de propiedad intelectual ${ }^{3} \mathrm{y}$, por último, artículo 44 de la CE, que recoge el derecho de acceso a la cultura. Este último se encuentra, sin duda, en una situación más precaria que la de sus pares a resultas de la posición que ocupa en el texto constitucional ${ }^{4}$. Lo mismo ocurre a nivel europeo: por un lado, no se encuentra explícitamente recogido en los textos de protección de derechos fundamentales, ni el Convenio Europeo de Derechos Humanos ${ }^{5}$ (en adelante, CEDH), ni la Carta Europea de Derechos Fundamentales $^{6}$ lo contemplan; por otro, no ha sido objeto de un desarrollo específico por parte de las políticas europeas, por mucho que la presencia de la voz cultura en las constituciones europeas, especialmente en los preámbulos, haya aumentado considerablemente (Häberle, 2017). Esto no supone que su presencia en el orden jurídico sea inexistente, pero queda diluida al someterse a la normativa desarrollada en materia de propiedad intelectual (Symonides, 1998); propiedad que

1 Unión europea. Propuesta de Directiva (UE) COM/2016/0593 final - 2016/0280 (COD) del Parlamento Europeo y del Consejo sobre los derechos de autor en el mercado único digital. Disponible en: https://eur-lex.europa.eu/legal-content/ES/TXT/HTML/?uri=CELEX:52016PC0593\&from=ES

2 Esta concreción ha sido deducida a partir de la redacción dada por el Pacto Internacional de Derechos Económicos, Sociales y Culturales (en adelante, PIDESC) y su contenido jurídico. En su artículo 15 el PIDESC reconoce el derecho a: a) participar en la vida cultural; b) gozar de los beneficios del progreso científico y de sus aplicaciones; c) beneficiarse de la protección de los intereses morales y materiales que le correspondan por razón de las producciones científicas, literarias o artísticas de que sea autora. [...] y añade que los Estados Partes se comprometerán a respetar la indispensable libertad para la investigación científica y para la actividad creadora [...].

${ }^{3}$ No se tendrá en cuenta aquí la distinción que realiza parte de la doctrina entre derechos de autor y derechos de propiedad intelectual, ya que, si bien es relevante, nos obligaría a entrar en un nivel de detalle que complicaría innecesariamente la explicación, puesto que tal distinción no afecta al análisis que nos ocupa. En cualquier caso, la mayoría de la doctrina española entiende el derecho de autor como un derecho único de naturaleza patrimonial (Cfr. De Román Pérez, 2005: 29).

${ }^{4}$ El artículo 44 se ubica en el Capítulo III de II Título II de la Constitución: Principios rectores de política social y económica y, por tanto, su grado de justiciabilidad es menor que la de los considerados derechos fundamentales (Cfr. Pedro de Prieto, 2006).

${ }^{5}$ Convenio para la Protección de los Derechos Humanos y de las Libertades Fundamentales, hecho en Roma el 4 de noviembre de 1950, ratificado por España con fecha 26 de septiembre de 1979, y publicado en el Boletín Oficial del Estado de 10 de octubre de 1979. Disponible en: https://www.boe.es/boe/dias/1999/05/06/pdfs/A16808-16816.pdf

${ }_{6}$ Proclamada por los Jefes de Estado y de Gobierno de los países miembros, reunidos en el Consejo Europeo celebrado en Niza el 7 de diciembre de 2000. 
en varias ocasiones limita el acceso a la cultura (Ramos Toledano, 2018), a pesar de que su justificación histórica se ha basado en la defensa de la transmisión cultural (Xalabarder, 2007-2008) ${ }^{7}$. La mencionada controversia en el Parlamento Europeo es buen ejemplo de ello: los detractores y partidarios de la propuesta se sitúan en el bando de las libertades digitales y en el de la protección de los derechos de autor, respectivamente. Es decir, no hay una reclamación fuerte, ni una concepción unificada del derecho de acceso a la cultura, que ocupa un papel secundario en la agenda de este debate europeo. En este escenario, se impone incorporar la perspectiva del derecho de acceso a la cultura. Ahora bien, ¿es posible configurar un tal derecho de acceso a la cultura en Europa? O dicho de otra manera, ¿existe realmente el derecho de acceso a la cultura? ${ }^{8}$ y si es así, ¿cuál es su contenido? Como ya se ha apuntado, el derecho positivo europeo no lo ha reconocido de manera expresa. Sin embargo, el Tribunal Europeo de Derechos Humanos (en adelante, TEDH) ha desplegado una labor de protección de los denominados "derechos culturales" 9 . Entre ellos se encuentra el derecho de acceso a la cultura amparado, en particular, en el artículo 10, que reconoce el derecho a la libertad de expresión, así como el derecho a recibir información ${ }^{10}$. Pero, ¿quiere esto decir que uno y otro son equivalentes, o tal vez quepa afirmar que la cultura goza de una protección cualificada respecto de la información? Las resoluciones del TEDH en la materia apuntan hacia una respuesta afirmativa. Este artículo examina la protección que el TEDH brinda al acceso a la cultura con el doble objetivo de: a) concretar el contenido jurídico del derecho de acceso a la cultura, para lo que se procederá a b) analizar la jurisprudencia más paradigmática del Tribunal Europeo de Derechos Humanos ${ }^{11}$.

\section{El contenido sí importa}

La tesis aquí defendida es que, a pesar de que el derecho de acceso a la cultura haya sido amparado en al artículo 10 del CEDH que protege el acceso a la información, uno y otro protegen bienes jurídicos distintos, aunque no independientes. La argumentación más relevante al respecto sostiene que para el TEDH los contenidos informativos con carácter cultural gozan de una protección

\footnotetext{
7 Efectivamente, la Directiva 2001/29/CE del Parlamento Europeo y del Consejo de 22 de mayo de 2001 relativa a la armonización de determinados aspectos de los derechos de autor y derechos afines a los derechos de autor en la sociedad de la información contempla determinadas excepciones (contenidas en los apartados 2 y 3 del artículo 5) en favor del acceso y la transmisión de la cultura. Así, limitan el derecho de propiedad intelectual en museos, bibliotecas, en el uso con fines de enseñanza, de crítica o de celebraciones religiosas, entre otros. Por tanto, el derecho de acceso a la cultura se presenta funcionalmente como un límite del derecho de autor.

${ }^{8}$ Las dudas planteadas no se cuestionan la existencia de un derecho humanos a la cultura (Ferri, 2015), sino de un derecho fundamental de acceso a la cultura, en el sentido de estar dotado de "potencial autodisposición por el titular del derecho y, a la vez, de existencia indisponible por el legislador"(Bastida Freijedo, 2004: 40).

9 Como así queda recogido en el informe Cultural rights in the case-law of the European Court of Human Rights, publicado en enero de 2011 (con posterior actualización en 2017). Este informe ha sido la fuente principal para este estudio. El informe se adhiere a una noción amplia y poco sistemática de "derechos culturales" y entre ellos se encuentra el que aquí nos ocupa, el derecho de acceso a la información.

${ }^{10}$ La redacción concreta del artículo es: "Toda persona tiene derecho a la libertad de expresión. Este derecho comprende la libertad de opinión y la libertad de recibir o de comunicar informaciones o ideas sin que pueda haber injerencia de autoridades públicas y sin consideración de fronteras. El presente artículo no impide que los Estados sometan las empresas de radiodifusión, de cinematografía o de televisión a un régimen de autorización previa".

${ }^{11}$ Finalidad que se inscribe en la tesis doctoral de la autora, actualmente en desarrollo. No se pretende por tanto, realizar un análisis dogmático exhaustivo que defina la naturaleza y estructura del derecho de acceso a la cultura. En este texto se parte de la premisa de que el derecho de acceso a la cultura es una vertiente del derecho a la cultura, como ya ha sido señalado.
} 
cualificada de manera que se está protegiendo el acceso a la cultura y no meramente la libertad de obtener información ${ }^{12}$.

\subsection{Acceso al arte}

El Caso Akdaş contra Turquía (16 de febrero de 2010), ilustra con elocuencia en qué sentido puede ser decisivo el carácter cultural del contenido al que se pretenda acceder. En esta ocasión el Tribunal se pronunció sobre la incautación de una novela. La demandante había publicado una traducción turca de la novela erótica Les onze mille verges del escritor francés Guillaume Apollinaire, que contiene descripciones gráficas de escenas de relaciones sexuales, con diversas prácticas como el sadomasoquismo o el vampirismo. La recurrente fue condenada por publicar material obsceno e inmoral susceptible de animar el deseo sexual entre la población.

EI TEDH reconoció la legitimidad de la injerencia en la libertad de expresión por parte de Turquía y reiteró que los requisitos morales variaban en función del tiempo y del lugar, incluso dentro del mismo Estado, al que concede un amplio margen de apreciación en el orden moral. Con todo, el Tribunal consideró que en tanto que esta obra forma parte del patrimonio literario europeo, la medida no podía entenderse como proporcionada. Su juicio se basó en tres razones: a) el transcurso de más de un siglo desde que el libro se publicó por primera vez en Francia (1907), b) su publicación en varios idiomas en un gran número de países, y c) el reconocimiento que ha obtenido gracias a su publicación en la prestigiosa serie "La Pléiade". Los argumentos que esgrime el Tribunal a la hora de determinar el carácter de patrimonio literario europeo no son de índole estética, como no puede ser de otra manera, pues no es a él a quien compete ejercer este tipo de autoridad en la materia ${ }^{13}$. Sin embargo, no por ello desconoce la condición y relevancia de la obra en la cultura europea. Es destacable su vocación objetiva: el alcance temporal y geográfico, y la calidad, que habría sido certificada por la casa editorial.

Dejando al margen los parámetros usados para apreciar su relevancia cultural, centrémonos en cómo ésta altera el resultado de la ponderación. Otras sentencias confirman cómo, en relación con la libertad de creación artística y el orden moral, el TEDH concede un amplio margen de apreciación a los países a la hora de interferir con el artículo 10 de la CEDH. A pesar de reconocer también en este caso la mejor cualificación del Estado frente al Tribunal para sopesar y ponderar los bienes jurídicos en juego, se introduce en la ecuación un nuevo factor que varía el resultado: el acceso al patrimonio cultural. La conclusión a la que llega el Tribunal es que "no se puede privar al público de una lengua determinada al acceso de una obra que forme parte del referido patrimonio" (Cfr. Caso Karataş contra Turquía, de 16 de febrero de 2010: § 52) ${ }^{14}$.

Por lo tanto, el bien cultural, cuya máxima expresión es su reconocimiento como componente del patrimonio europeo, goza de un grado de protección no predicable de cualquier otra manifestación o expresión de información. Tanto es así,

\footnotetext{
12 Pese a lo cual es necesario reconocer que la ausencia de una definición clara de qué sea cultura por parte del TEDH dificulta este objetivo.

13 Este efecto ha sido puesto de relieve en algunos casos sobre la libertad de creación artística, en los que el Tribunal no expone un juicio estético directo, pero atribuye a una obra cualidades típicas del arte, como "una profunda expresión de angustia" y le concede así un grado de protección mayor (Cfr. Caso Karataş contra Turquía, 2010: § 52).

${ }^{14} \mathrm{La}$ traducción es nuestra.
} 
que la ratio no se basa en un derecho de libertad de expresión de la demandante, sino en el acceso por parte de los ciudadanos turcos a la obra literaria ${ }^{15}$.

En cambio, en el Caso Ehrmann y SCI VHI contra Francia (7 de junio de 2011), se contraponen dos bienes jurídicos culturales. Por un lado, el derecho a la libertad de creación artística; por otro, la preservación del patrimonio histórico. Un artista visual convirtió una propiedad en una residencia de artistas. Sin embargo, introdujo modificaciones que afectaban a la fachada, considerada monumento histórico $y$, por tanto, al impacto visual de la panorámica de los edificios históricamente protegidos, sin haber seguido los procedimientos obligados por la ley. De este modo, no solo está en juego la afección del derecho de libertad de expresión del artista, sino que de hecho se limita el acceso de un alto número de visitantes interesados en las obras. En último término, se enfrentan dos derechos relativos a la cultura. El TEDH se decanta por hacer prevalecer el respeto a las normas que aseguran el patrimonio cultural (siempre previo examen de proporcionalidad), de lo cual no cabe, sin embargo, deducir un carácter general que privilegie uno sobre otro, pues el TEDH deja clara constancia del carácter mínimo que la injerencia ejerce en este caso sobre el derecho de creación artística.

\subsection{Cultura democrática y pluralismo}

Según el Tribunal, la sátira es una forma de expresión artística, así como una crítica social que, por el carácter inherente de exageración y distorsión de la realidad busca por su naturaleza provocar y agitar. Por tanto, le confiere a la sátira un estatuto artístico, por un lado; pero además refuerza su protección, ya que entiende que al ser la provocación parte de la naturaleza de la sátira, eliminar los elementos molestos de la misma pasaría por desnaturalizarla. Así lo expresa en el Caso Vereinigung Bildender Künstler contra Austria, mediante la siguiente afirmación: "la sátira es una forma de expresión artística y comentario social y, por sus características inherentes y exageración y distorsión de la realidad, tiene vocación de provocar y agitar. En consecuencia, cualquier interferencia con un derecho del artista debe ser examinada con particular cuidado" (25 de enero de 2007: § 33). Si en este caso se produce una mayor protección de la manifestación artística por sus implicaciones políticas, también se da el fenómeno contrario. Así, en el caso Karatas contra Turquía, el demandante, que pertenecía al pueblo kurdo, había sido condenado por escribir poemas con alto contenido de violencia y que incitaban separatismo. Sin embargo, y aunque el TEDH coincidió en este extremo, afirmó que la expresión artística se vale de recursos retóricos, como la metáfora, de modo que no cabe aplicar la interpretación literal a una obra de contenido artístico. No hay un llamamiento a la insurrección, entiende el TEDH, sino una expresión de angustia sobre la situación política (caso Karatas contra Turquía, 8 de julio de 1999: § 54).

Por consiguiente, parece apuntarse cierta vinculación entre la protección del arte y los valores democráticos y políticos en juego: de ahí la protección reforzada que se brinda a la manifestación artística, ya que a menudo se presenta como idónea para expresar un malestar social o político. Esto redunda en la idea del espacio público europeo como la "actualización de la pluralidad cultural" (Häberle, 2017:10). Relación que se da asimismo entre la producción científica y los valores democráticos, como veremos a continuación, en relación con la plataforma digital Youtube.

\footnotetext{
15 También el caso de la fiscalía contra Ahmad Al Faqi Al Mahd (2018) refuerza la idea del valor de los bienes culturales, ya que fue la primera condena de la Corte Penal Internacional por destrucción de patrimonio cultural. En este caso declaró culpable de un crimen de guerra a quien destruyó nueve mausoleos en Tumbuctú inscritos en la Lista del Patrimonio Mundial.
} 


\section{Dimensión relativa y dinámica de la cultura}

En este apartado quiere ponerse de relieve que el contenido es clave, pero no es el único factor determinante. Si del derecho de acceso a la cultura se trata, no solo importa aquello que sea cultura, sino también qué entendemos por "acceso". Aquí se defiende que no tiene el mismo peso un "acceso" que se agote en sí mismo, que la idea de transmisión, mucho más acorde con la noción de cultura. Además, deben tenerse en cuenta las posibilidades reales del acceso a través de canales culturales alternativos.

En el Caso Cengiz y otros contra Turquía (1 de diciembre de 2015) un tribunal penal de Ankara determinó que diez vídeos compartidos en Youtube habían infringido la prohibición penal de insultar la memoria del Mustafa Kemal Atatürk, fundador del Estado moderno de Turquía, e impusieron una orden de bloqueo en todo el sitio web. Los demandantes, tres profesores universitarios de derecho, denunciaron esta medida frente a los tribunales turcos, que desestimaron su petición, e interpusieron un recurso ante el TEDH. Afirmaron que utilizaban la plataforma para acceder a vídeos relacionados con sus actividades profesionales y para descargar y compartir estos materiales, lo que permitió al TEDH concederles el estatus de víctimas $y$, por tanto, legitimación subjetiva en el proceso. Los recurrentes argumentaron que la orden de bloqueo había afectado a sus actividades académicas y que había un amplio interés público en tener acceso a YouTube. El TEDH declaró la violación del artículo 10 del CEDH, pues, aunque el bloqueo de la web no afectaba de manera directa a los recurrentes, estos no eran meros usuarios, sino que la usaban para fines profesionales. EI TEDH admitió a trámite la demanda, por lo que, la finalidad científica que tenía el uso de la web permitió a los demandantes recurrir al TEDH. En este sentido, las garantías del acceso a la información quedaron reforzadas, debido a las alegaciones de los propios demandantes (que consideraron la finalidad de la información como elemento relevante).

Pero no por ello cualquier injerencia en el acceso de los usuarios es suficiente para declarar la violación del artículo ${ }^{10}$. Así, por ejemplo, en el Caso Akdeniz contra Turquía (11 de marzo de 2014), la división de medios de comunicación de la fiscalía ordenó el bloqueo del acceso a los sitios web Myspace.com y Last.fm, alegando que estos sitios difunden obras musicales que infringen los derechos de autor. Sin embargo, el mero hecho de que el demandante -al igual que los demás usuarios turcos de los sitios web en cuestión- se hubiera visto afectado indirectamente por una medida de bloqueo no bastaba para que se le considerara una víctima a efectos del artículo 34 de la CEDH. Como usuario de internet, el solicitante había hecho uso de sus servicios y se le había privado de un único medio de escuchar música, entre muchos otros. Por lo tanto, podría haber tenido acceso sin dificultad a una amplia gama de temas musicales por numerosos medios sin que ello implicase una violación de las normas sobre derechos de autor.

\section{Cultura frente a terceros. Los derechos de autor}

Precisamente estos dos casos se enmarcan en el mismo entorno internauta al que refiere el debate europeo con que se daba comienzo al texto. En este ámbito, los derechos de autor han sido reforzados, a pesar de que en muchos casos pueden colisionar y suponer una merma del acceso a la cultura. Por eso, es especialmente importante el Caso Ashby, Donald y otros contra Francia (10 de enero de 2013), que reconoce los derechos garantizados por el artículo 10 como un límite de los derechos de autor. Los demandantes eran tres fotógrafos de moda, condenados en 
Francia por infracción de los derechos de autor a raíz de la publicación de imágenes en internet de una empresa de moda. Las fotos fueron tomadas en los desfiles de moda en París en 2003 y publicadas sin el permiso de las marcas. Los recurrentes denunciaron en Estrasburgo la vulneración de los derechos que les asisten en virtud del artículo 10 del CEDH. El Tribunal declaró que el recurso era admisible, pero llegó a la conclusión de que la condena de los demandantes por violación de la ley francesa de derechos de autor no constituía una violación de sus derechos. Este caso supone el primer pronunciamiento del TEDH en una sentencia de fondo acerca de los límites de los derechos de autor. En concreto, el Tribunal afirmó que una condena basada en la violación de los derechos de autor es susceptible de interferir con el artículo 10 del CEDH. La justificación de cualquier restricción del artículo 10 basada exclusivamente en la infracción de los derechos de autor será insuficiente, por lo que es necesario el ejercicio de la ponderación y no hay, por tanto, una prevalencia automática de los derechos de autor que exima del cumplimiento del artículo 10.

\section{5. ¿Qué es el derecho de acceso a la cultura? Penúltima reflexión}

En atención a las sentencias que acaban de ser presentadas parece posible concluir que el TEDH brinda una protección cualificada a determinados contenidos informativos que podrían identificarse como contenidos culturales ${ }^{16}$. La cuestión de qué sea cultura ha sido, sin duda, debatida desde diferentes disciplinas: sociología, antropología o filosofía. Sin embargo, desde el punto de vista de las garantías de los derechos fundamentales se hace imprescindible recuperar también un contenido eminentemente jurídico. Para ello es necesario concretar algunas de las nociones tan amplias que se han dado de cultura, ya sea cultura en términos universalistas o en términos étnicos (Prieto de Pedro, 1993). En este sentido, y, repito, para los efectos que nos ocupan, y no con la intención de aproximarnos a una concepción de la cultura, el TEDH aporta una información valiosa.

Por un lado, presenta una jurisprudencia coherente con las declaraciones internacionales en derechos humanos, que al hablar del derecho a participar en la cultura realizan una mención especial al arte, la literatura y la ciencia. Ha quedado aquí expuesto el mayor grado de protección que se concede a los individuos a través del artículo 10 del CEDH para acceder (o expresar) obras consideradas manifestaciones de arte, literatura o medios de divulgación científica, lo que hace pensar en ellos como contenidos privilegiados. Huelga decir que esta noción de cultura se corresponde con la concepción universalista, dejando de lado la noción étnica de cultura. Sin embargo, una y la otra no son contradictorias, en la medida en que este "núcleo duro" (arte y ciencia) es una "manifestación de forma" (Prieto de Pedro, 2008: 209) de la cultura; núcleo que puede expresar un contenido relativo a la cultura en sentido étnico, como ocurría en el Caso Karatas contra Turquía, en el que el demandante expresaba su sentir como parte del pueblo kurdo.

También han sido apuntadas las relaciones del derecho de acceso a la cultura con otros derechos culturales: el derecho de creación artística o los derechos de autor. En relación con el primero, el Tribunal ha incidido en cómo la sátira es un ejemplo de expresión artística que forma parte de la cultura occidental, pero que merece además una protección especial ya que estimula el debate, la crítica y el pluralismo político. En cuanto a los derechos de autor, tema que daba comienzo a esta voz, más allá del reconocimiento positivo con que cuenta a nivel nacional o

\footnotetext{
${ }^{16}$ Si bien es cierto que para ello se ha recurrido al marco del artículo 10 , esto ha sido a costa de realizar una interpretación extensiva que de facto está protegiendo el derecho humano de acceso a la cultura.
} 
europeo, el TEDH ha estipulado que también debe ser sometido a límites en la medida en que puede suponer una interferencia con el artículo 10 del $\mathrm{CEDH}$. Estos vínculos, que han sido comentados de manera somera aquí, nos permiten hablar de una noción de cultura transversal al resto de derechos y que, por tanto, se despliega de manera compleja en ellos. Esto, por cierto, ha dificultado su estudio. Por ello, para determinar su alcance y sus límites se hace necesario analizar la relación y la presencia del acceso a la cultura en estos otros derechos, en especial en el derecho de propiedad intelectual. De todas las que aquí se han tratado, esta cuestión sea seguramente aquella con más recorrido en futuras investigaciones, ya que el interrogante "¿qué es el derecho a la cultura?" expresa el deseo de dar una adecuada cobertura a la transmisión cultural frente a la mercantilización de los derechos culturales (Amoedo Souto, 2014: 311).

Además, el acceso a la cultura se plantea en términos relativos y dinámicos, es decir, de transmisión y flujo de la cultura. Relativos, porque el efectivo impedimento del acceso a un contenido a través de una vía en concreto no supone automáticamente la vulneración del derecho, sino que este obstáculo debe dificultar seriamente el acceso (por ejemplo, por la inexistencia de otras vías, para acceder a tales contenidos) y, por tanto, depende de cuántas otras vías existan. Lo segundo porque, como vimos en Cengiz contra Turquía, hay una consideración teleológica del acceso a la cultura, mediante la que se presta una protección mayor al acceso si no se agota en sí mismo, sino al compartir, generar o transmitir cultura (en este caso en particular, ciencia). Esta característica apunta a la dimensión objetiva del derecho, en la que se apoya, por ejemplo, la protección especial de la sátira o la divulgación científica, susceptibles ambas de contribuir al debate crítico de la sociedad. Así, se pone de relieve su carácter funcional, pues ya no se trata solo de defender un derecho subjetivo, sino de consolidar los principios democráticos.

Pero, ¿podría hablarse del acceso a la cultura como un derecho subjetivo? Primero, debe determinarse si el acceso a la cultura consiste exclusivamente en una vertiente concreta de un derecho más amplio a la información o si hay motivos para defender su autonomía. El Caso Akdaş contra Turquía nos permite adelantar una respuesta positiva. Si esto fuera así, podríamos afirmar también que la protección del derecho de acceso a la cultura no se agota en su más que reivindicado contenido prestacional. Por el contrario, en virtud de su estructura, es decir, de la facultad que otorga a su titular (Díez-Picazo, 2013: 35) puede considerarse un derecho de defensa: no exclusivamente en el sentido de una debida "abstención del Estado" (Caso Akdaş contra Turquía, 16 de febrero de 2010), sino también en el del deber del Estado de actuar frente a impedimentos externos para acceder a la cultura (Caso Ashby, Donald y otros contra Francia, 10 de enero de 2013).

\section{Bibliografía}

AMOEDO SOUTO, C. A. (2014), "El derecho de acceso a la cultura en España: diagnóstico y propuestas de estrategia jurídica", R.V.A.P., núm. especial 99100, pp. 295-327.

BASTIDA FREIJEDO, F.J., VILLAVERDE MENÉNDEZ, I., VVAA, (2004), Teoría general de los derechos fundamentales en la Constitución española de 1978, Tecnos, Madrid.

DE ROMÁN PÉREZ, R. (2005), "Naturaleza jurídica del derecho de autor". En: Propiedad intelectual, derechos fundamentales y propiedad industrial, Madrid, Editorial Reus, pp. 13-48. 
FERRI, M. (2015), Dalla partecipazione all'identità. L'evoluzioni della tutela internazionale dei diritti culturali, Vita e Pensiero, Pubblicazioni dell'Università Cattolica del Sacro Cuore, Milán.

HÄBERLE, P. (2017), "La ciencia jurídica europea como ciencia de la cultura", Revista de derecho constitucional europeo, núm. 27, pp. 177-198.

PRIETO DE PEDRO, J. (1993), Cultura, culturas y constitución, Centro de Estudios Constitucionales, Madrid.

PRIETO DE PEDRO, J. (2006), "Artículo 44.1: el derecho a la cultura". En: Vlex, Tomo IV, Artículos 39 a 55 de la Constitución Española de 1978, pp. 205-216, Disponible en la siguiente dirección electrónica: https://libros-revistasderecho.vlex.es/vid/articulo-44-1-derecho-cultura-331403 (fecha de consulta: 10 de enero de 2019).

RAMOS TOLEDANO (2018), Propiedad digital. La cultura en internet como objeto de cambio, Trotta, Madrid.

TRIBUNAL EUROPEO DE DERECHOS HUMANOS (2007), Sentencia caso Vereinigung Bildender Künstler contra Austria, 25 de enero de 2007.

TRIBUNAL EUROPEO DE DERECHOS HUMANOS (2010a), Sentencia caso Akdaş contra Turquía, 16 de febrero de 2010.

TRIBUNAL EUROPEO DE DERECHOS HUMANOS (2010b), Sentencia caso Karataş contra Turquía, de 5 de abril de 2010.

TRIBUNAL EUROPEO DE DERECHOS HUMANOS (2011), Sentencia caso Ehrmann y SCI VHI contra Francia, de 7 de junio de 2011.

TRIBUNAL EUROPEO DE DERECHOS HUMANOS (2013), Sentencia caso Ashby, Donald y otros contra Francia, de 10 de enero de 2013.

TRIBUNAL EUROPEO DE DERECHOS HUMANOS (2015), Sentencia caso Cengiz y otros contra Turquía, de 1 d diciembre de 2015.

TRIBUNAL EUROPEO DE DERECHOS HUMANOS (2017), Cultural rights in the case-law of the European Court of Human Rights, disponible en la siguiente dirección electrónica: https://www.echr.coe.int/Documents/Research_report_cultural_rights_ENG.pdf. (fecha de consulta: 10 de marzo de 2019).

SYMONIDES, J. (1998), "Cultural rights: a neglected category of human rights", International Social Science Journal, $\mathrm{N}^{\circ} 158$, UNESCO, disponible en la siguiente dirección electrónica: https://onlinelibrary.wiley.com/doi/10.1111/14682451.00168 (fecha de consulta: 10 de marzo de 2019)

XALABARDER, R. (2007-2008), "Derecho de autor: el desarrollo de los objetivos de protección. ¿Cuán lejos hemos evolucionado desde las raíces?”. En: Actas de Derecho Industrial y Derecho de Autor, Tomo 28, pp. 529-545. 